\title{
AVALIAÇÃO DE FATORES E VARIÁVEIS QUE INFLUENCIAM A SUSTENTAÇÃO DE PROGRAMAS DE MELHORIA CONTÍNUA NA VISÃO DE ESPECIALISTAS
}

\section{RESUMO}

Este trabalho tem por finalidade identificar os fatores e as variáveis que influenciam na sustentação dos programas de melhoria contínua. Utilizou-se de um estudo exploratório, através de uma análise qualitativa, com especialistas qualificados na metodologia Lean Six Sigma e de grande experiência em implantação para qualificar os fatores e variáveis. Os resultados, os quais foram discutidos e posteriormente reclassificados com base na literatura consultada geraram um conjunto de variáveis associadas a fatores que influenciam a sustentação dos programas de melhoria contínua. Os fatores estão relacionados ao uso técnico da metodologia, mas envolvem outros 12 fatores entre os quais: alinhamento estratégico, estrutura de comunicação, envolvimento da liderança, aspectos culturais, de governança, treinamento, suporte de recursos humanos, aprendizagem organizacional, premiação e reconhecimento, infraestrutura, suporte de especialistas e visão no cliente.

Palavras-chave: Melhoria Contínua; Lean Six Sigma; Sustentação dos Programas de Melhoria Contínua.

\section{FACTORS EVALUATION AND VARIABLE THAT INFLUENCE THE IMPROVEMENT PROGRAMS IN CONTINUOUS SUPPORT SPECIALISTS VISION}

\begin{abstract}
This work has the objective to identify the factors and variables that make influence at sustainability of continuous improvement programs. It has done an exploratory study, by the quality analysis, with qualified experts in Lean Six Sigma methodologies and huge experience to implement these projects to qualify the factors and variables. The results, which ones were discussed and resort by literature basis generated a package of variables related with factors that make influence to sustainability of continuous improvement programs. Factors are related technical aspects but also involve other 12 factors like: strategic alignment, communication, leadership involvement, culture, governance, training, human resources support, learning organization, reward and recognition, infrastructure, experts support and client vision.
\end{abstract}

Keywords: Continuous Improvement; Lean Six Sigma; Support of continuous improvement programs 


\section{FACTORES DE EVALUACIÓN Y VARIABLE QUE INFLUYEN EN LOS PROGRAMAS DE MEJORA CONTINUA EN ESPECIALISTAS DE SOPORTE VISIÓN}

\section{RESUMEN}

Este estudio tiene como objetivo identificar los factores y variables que influyen en apoyo de programas de mejora continua. Se utilizó un estudio exploratorio, a través de un análisis cualitativo, con expertos cualificados en la metodología Lean Seis Sigma y una amplia experiencia en la implementación de calificar los factores y variables. Los resultados, que fueron discutidas y posteriormente se reclasifica basan en la literatura genera un conjunto de variables asociadas a los factores que influyen en el apoyo de programas de mejora continua. Los factores están relacionados con el uso técnico de la metodología, sino que implican otros 12 factores que incluyen: alineación estratégica, estructura de comunicación, la participación de la dirección, culturales, gobernabilidad, capacitación, apoyo, recursos humanos, aprendizaje organizacional, premios y reconocimiento, infraestructura, especialistas de apoyo y la visión en el cliente.

Palabras clave: Mejora Continua; Lean Six Sigma; Apoyo de programas de mejora continua.

Roberto Jorge Junior ${ }^{1}$ Dirceu Da Silva ${ }^{2}$ Roque Rabechini Junior ${ }^{3}$

\footnotetext{
${ }^{1}$ Doutor em Administração pela Universidade Nove de Julho - UNINOVE. Professor de MBA na Universidade Mackenzie e FECAP. Brasil. E-mail: roberto.jorge.junior@accenture.com

2 Doutor em Educação pela Universidade de São Paulo - USP. Professor do Programa de Pós-Graduação em Administração da Universidade Nove de Julho - PPGA/UNINOVE. Brasil. E-mail: dirceus@uni9.pro.br

${ }^{3}$ Doutor em Engenharia de Produção pela Escola Politécnica da Universidade de São Paulo - POLI/USP. Professor do Programa de Mestrado Profissional em Administração - Gestão de Projetos da Universidade Nove de Julho - PMPAGP/UNINOVE. Brasil. E-mail: roquejr@uni9.pro.br
} 


\section{INTRODUÇÃO}

O cenário econômico mundial tem se tornado cada vez mais dinâmico em função das necessidades de mudanças propiciadas pelos clientes e consumidores que requerem produtos e serviços inovadores ou eficazes para atender suas necessidades de consumo (Vanhonacker \& Verbeke, 2014). Dessa forma, as indústrias de manufatura e transformação, bem como as empresas de prestação de serviços, têm buscado se aprimorar continuamente de maneira a alavancar sua competitividade e flexibilidade, através de programas de transformação ou melhoria contínua, para essas criarem ou sustentarem suas vantagens competitivas (Snee, 2010). Muitos projetos para se buscar a excelência e melhoria contínua têm sido trilhados internamente pelas empresas com diferentes objetivos de atenderem às necessidades de mercado: altos níveis de qualidade, maior eficiência operacional, melhor confiabilidade e maior agilidade na entrega (Liker, 2005). Além disso há uma necessidade emergente para que os benefícios gerados através dos programas de transformação sejam capturados e se sustentem ao longo do tempo e que repercutam no bottom line dos resultados da empresa (Yunus e Weber, 2010).

Pesquisas científicas sobre os conceitos de Lean Manufacturing, Seis Sigma e melhoria contínua de um modo mais abrangente já evidenciavam desde 1999 que muitas empresas já faziam uso dos conceitos de Lean originados na Toyota, mas que não tinham o sucesso e a sustentação dos resultados como era evidente na Toyota, mesmo ela tendo apresentando de forma bastante transparente a sua metodologia de implantação, pois como sustentam Spear e Bowen (1999), existiam elementos de aprendizagem contínua e foco na solução de problemas, bem como características culturais enraizadas na empresa, que faziam com que ela incorporasse os conceitos de melhoria contínua na sua prática diária.

Esses elementos qualificavam e diferenciavam a Toyota das demais organizações e as fizeram referência na implantação de programas de melhoria contínua por muitos anos. Mesmo Senge et al (1994) já sinalizavam a importância da aprendizagem organizacional como elemento de sucesso para uma empresa através das cinco disciplinas, acrescentando que a aprendizagem contínua possibilita gerar sempre um conhecimento novo, importante para compartilhar cultura e incorporar a melhoria contínua nas atividades do dia a dia. Liker (2005), acrescentou à aprendizagem organizacional, o fator trabalho colaborativo como relevante para a sustentação dos programas de melhoria contínua, ao qual na sua visão para que um programa seja sustentável a organização deve atender a necessidade da estratégia de longo prazo, ter processos estáveis e padronizados, apresentar boa relação com fornecedores e parceiros e ser uma organização de aprendizagem com foco na solução de problemas.
Nesse sentido, Bourne, Kennerley e FrancoSantos (2005) e Henry (2006) incluem o tema gestão de desempenho como fator de sustentabilidade da melhoria contínua, afirmando que existe uma sequência estruturada de se buscar o alto desempenho, que é desde a utilização de ferramentas de melhoria contínua tais como Lean Manufacturing (Ohno, 1997) e Seis Sigma passando pelo monitoramento com sistemas de desempenho de medição, e fechando o ciclo no engajamento e motivação das pessoas. Ou ainda na visão de Bhuiyan e Baghel (2005), o desafio de realizar bons programas de melhoria contínua com resultados sustentáveis vai muito além da aplicação técnica dos seus conceitos e ferramentas.

Em sintonia com o desafio apresentado, Bhuiyan e Baghel (2005), afirmam que embora existam bons programas de melhoria contínua implantados, os projetos realizados dentro desses programas não atingem maturidade e não se sustentam nas empresas, tirando o mérito dos próprios programas, pois para eles, os projetos são implantados simplesmente para solucionar um problema específico, os quais ferramentas são aplicadas, modelos operacionais e procedimentos são alterados e reescritos, equipes são treinadas e a liderança colhe resultados com esta implantação, ou seja os projetos são frutos das técnicas e ferramentas de sucesso do Lean já muito difundidas pelo Sistema Toyota de Produção. Contudo, para atingir sustentação, uma abordagem de melhoria contínua deve ser integrada alinhando os conceitos técnicos de eliminação de desperdícios e melhoria da qualidade, a elementos de gestão e governança, à aspectos humanos de aprendizagem contínua e colaboração, de forma a utilizar uma abordagem holística utilizando metodologias complementares e híbridas. Nesse intuito, o objetivo deste trabalho foi identificar de fato, quais fatores influenciam a sustentação de um programa de melhoria contínua.

E a questão a qual este trabalho buscou responder foi que fatores influenciam a sustentação de um programa de melhoria contínua?

Uma vez mostrada a problemática geral do trabalho segue a apresentação do referencial teórico da pesquisa. Por razões de espaço, o referido referencial será apresentado de forma sintética. Assim, foram usadas três teorias:

- Teoria sobre as metodologias e abordagens de processos de excelência operacional e melhoria contínua, que apresenta os conceitos e o contexto evolutivo (Lean, Six Sigma e Lean Six Sigma) das ferramentas de melhoria contínua e os objetivos de como aplicar a metodologia na execução dos projetos diante de um programa de transformação. Apresenta também as capabilidades requeridas para a condução de um programa de melhoria contínua. 
Avaliação de Fatores e Variáveis que Influenciam a Sustentação de Programas de Melhoria Contínua na Visão de Especialistas

- Teoria de aprendizagem organizacional, que discorre sobre a trajetória de aprendizagem organizacional nas empresas, buscando entender os elementos preponderantes de uma organização voltada ao aprendizado e também o impacto gerado na solução contínua de problemas.

- Teoria sobre maturidade, que apresenta as definições dos níveis de maturidade e em seguida relata sobre a importância da gestão no acompanhamento dos programas de melhoria contínua.

A figura 01 ilustra as teorias apresentadas, as quais foram resgatadas para este estudo com um enfoque de avaliação e entendimento delas na sustentação dos programas de melhoria contínua:

Figura 1 - Arcabouço Teórico básico para o desenvolvimento da pesquisa

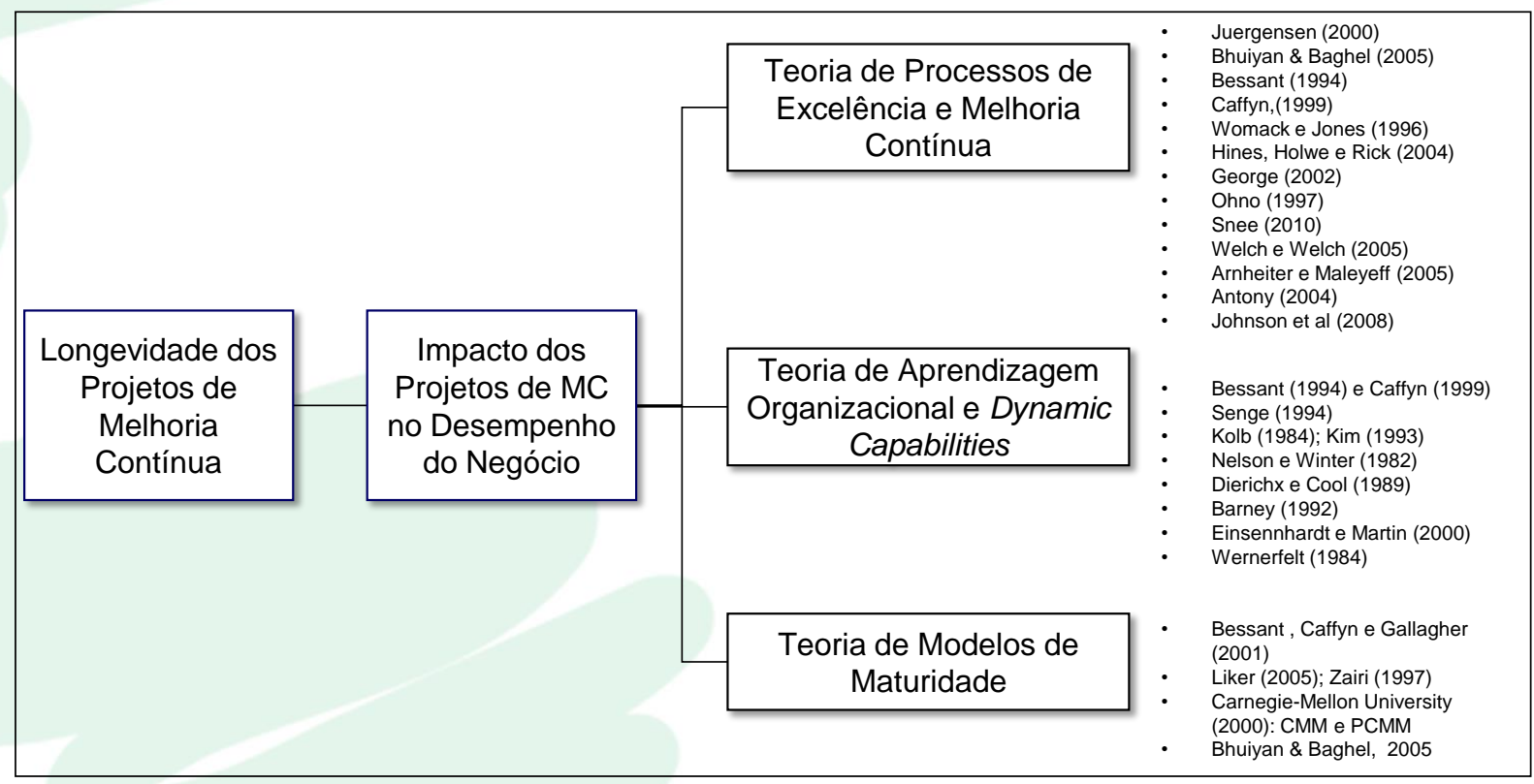

\section{PROCEDIMENTOS METODOLÓGICOS}

Os procedimentos metodológicos deste trabalho tiveram como definição a pesquisa qualitativa e exploratória, partindo-se da revisão da literatura para fundamentar e extrair os elementos iniciais e em um segundo momento foram apresentados a cinco especialistas, configurando ao todo um processo de quatro etapas. O quadro 1 apresenta o perfil dos já apontados especialistas:

\begin{tabular}{|c|c|c|c|c|c|}
\hline Perfil Especialistas & Especialista 01 & Especialista 02 & Especialista 03 & Especialista 04 & Especialista 05 \\
\hline Formação & $\begin{array}{l}\text { Engenheiro } \\
\text { Mecânico }\end{array}$ & $\begin{array}{l}\text { Engenheiro } \\
\text { Mecânico }\end{array}$ & $\begin{array}{l}\text { Engenheiro } \\
\text { Mecânico }\end{array}$ & $\begin{array}{l}\text { Engenheiro } \\
\text { Mecânico }\end{array}$ & $\begin{array}{l}\text { Engenheiro } \\
\text { Produção }\end{array}$ \\
\hline Mestrado & $\begin{array}{l}\text { Engenharia } \\
\text { Mecânico }\end{array}$ & $\begin{array}{l}\text { Engenharia } \\
\text { Mecânico }\end{array}$ & $\begin{array}{l}\text { Engenharia } \\
\text { Mecânico }\end{array}$ & $\begin{array}{l}\text { Engenharia } \\
\text { Mecânico }\end{array}$ & Adm Empresas \\
\hline Doutorado & $\begin{array}{l}\text { Engenharia } \\
\text { Mecânico }\end{array}$ & N/A & Adm Empresas & $\begin{array}{l}\text { Engenharia } \\
\text { Mecânico }\end{array}$ & N/A \\
\hline $\begin{array}{c}\text { Certificação em } \\
\text { Melhoria Contínua }\end{array}$ & Black Belt & $\begin{array}{l}\text { Gold em Lean } \\
\text { Manufacturing }\end{array}$ & $\begin{array}{c}\text { Master Black } \\
\text { Belt }\end{array}$ & $\begin{array}{l}\text { Gold em Lean } \\
\text { Manufacturing }\end{array}$ & $\begin{array}{c}\text { Master Black } \\
\text { Belt }\end{array}$ \\
\hline Anos de Experiência & 14 & 15 & 14 & 17 & 10 \\
\hline Atuação na Operação & Sim & Não & $\mathrm{Sim}$ & Não & Não \\
\hline $\begin{array}{c}\text { \# Projetos de } \\
\text { Melhoria Contínua } \\
\text { Realizados }\end{array}$ & $>200$ projetos & $>300$ projetos & > 300 projetos & $\begin{array}{c}500 \text { projetos } \\
\text { aprox. }\end{array}$ & $>100$ projetos \\
\hline
\end{tabular}


Avaliação de Fatores e Variáveis que Influenciam a Sustentação de Programas de Melhoria Contínua na Visão de Especialistas

\begin{tabular}{|c|c|c|c|c|c|}
\hline $\begin{array}{l}\text { Segmentos de } \\
\text { Especialidade }\end{array}$ & $\begin{array}{l}\text { Industria } \\
\text { automobilística; } \\
\text { Indústria } \\
\text { química }\end{array}$ & $\begin{array}{l}\text { Indústria } \\
\text { Automobilística; } \\
\text { Bens de } \\
\text { Consumo; } \\
\text { Bancos; Bens de } \\
\text { Capital; } \\
\text { Telecom; } \\
\text { Farmacêutica }\end{array}$ & $\begin{array}{l}\text { Indústria } \\
\text { Automobilística; } \\
\text { Bens de } \\
\text { Consumo; } \\
\text { Bancos; Bens de } \\
\text { Capital; } \\
\text { Telecom; Oil \& } \\
\text { Gás; } \\
\text { Infraestrutura; } \\
\text { Governo }\end{array}$ & $\begin{array}{l}\text { Indústria } \\
\text { Automobilística; } \\
\text { Bens de } \\
\text { Consumo; } \\
\text { Bancos; Bens de } \\
\text { Capital; } \\
\text { Telecom }\end{array}$ & $\begin{array}{l}\text { Indústria } \\
\text { Automobilística; } \\
\text { Bens de } \\
\text { Consumo; } \\
\text { Bancos; Bens de } \\
\text { Capital; } \\
\text { Telecom; Oil \& } \\
\text { Gás; } \\
\text { Infraestrutura; } \\
\text { Governo }\end{array}$ \\
\hline
\end{tabular}

O trabalho dos especialistas foi realizado em quatro etapas. A figura 2 mostra sinteticamente o processo realizado com os mesmos. Assim, o processo compreendeu quatro etapas distintas. A saber:

Figura 2 - Processo de identificação de fatores e variáveis para a sustentação de um programa de melhoria contínua através do estudo exploratório

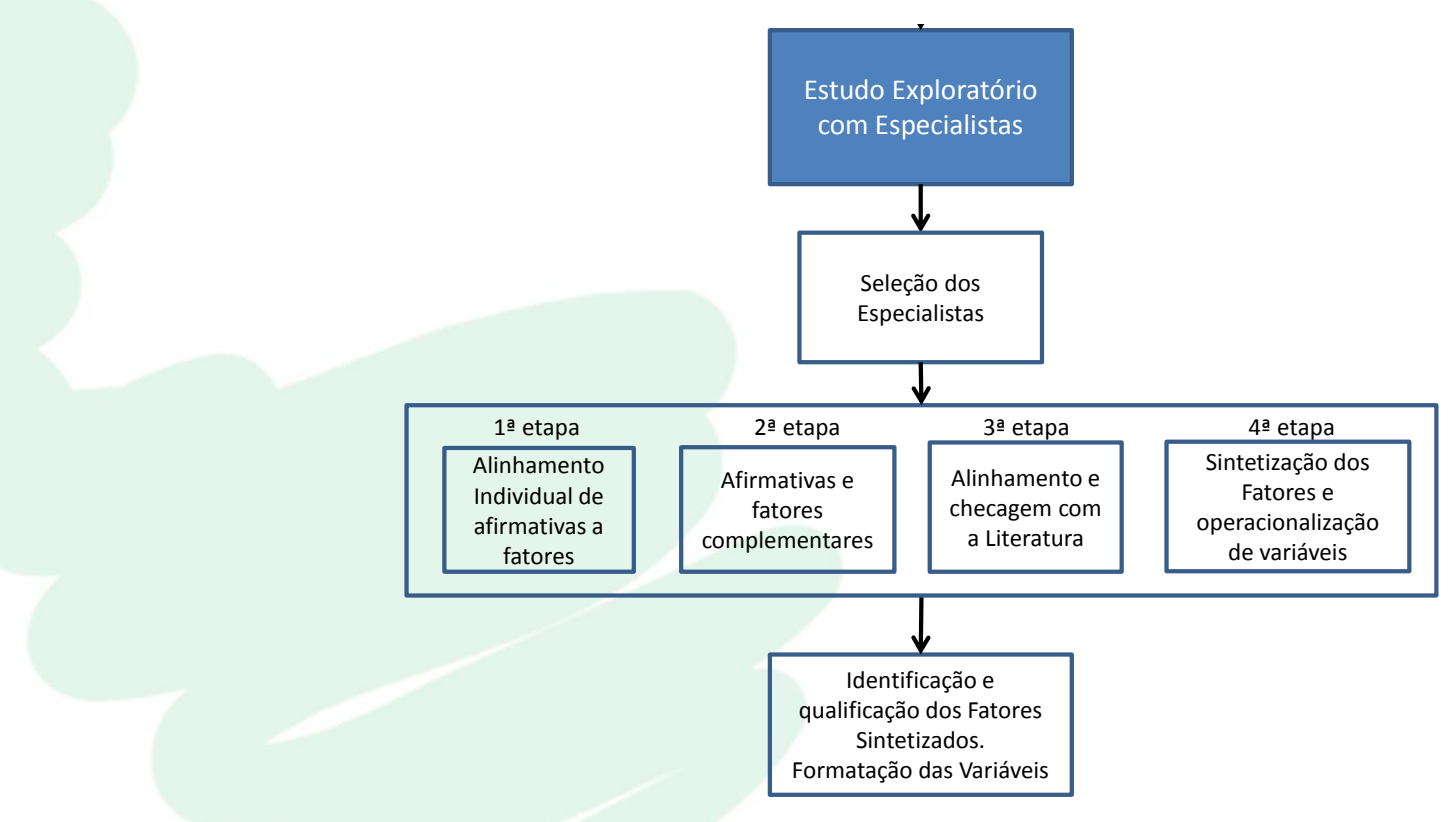

\subsection{Revisão da Literatura}

A consulta a literatura consistiu em pesquisar e analisar artigos dentro de um contexto de melhoria contínua, para os últimos dez anos no cenário científico com foco em artigos aprovados (texto completo) e revisados.

A pesquisa foi realizada sobre a metodologias de melhoria contínua mais evoluída, Lean Six Sigma, e contemplou também a intersecção com aprendizagem organizacional e níveis de maturidade. Como resultado, encontrou-se uma base de 138 artigos, dos quais identificou-se que em apenas doze estavam presentes fatores de sucesso ou fatores impeditivos, mencionados explicitamente pelos autores, na implantação ou aplicação dos programas de melhoria contínua. A estes 12 artigos (Banuelas, R.; Coronado, J. e Antony (2002); Bhuiyan e Baghel (2005); Amar e Davis (2008); Timans, Antony, Ahaus e Solingen (2012);
Antony, Kumar e Labib (2007); Manville, Greatbanks, Krishnasamy, David e Parker (2012); Andrietta e Miguel (2012); Oprime e Mendes (2011); Trad e Maximiano (2009); Hilton, Balla e Sohala (2008); Snee (2010), Arnheiter e Maleyeff (2005); foi adicionado o livro clássico e pioneiro, The Toyota Way de Liker (2005). Esses doze artigos e o livro clássico continham afirmativas e fatores relacionados a implantação ou meios de sustentar a melhoria contínua nas organizações, destacadas como fatores críticos de sucesso ou fatores impeditivos. Estas afirmativas e fatores foram então rotuladas no trabalho e utilizados no questionário que foi explorado com os especialistas.

Um conjunto de 103 afirmativas e sete fatores foram extraídos da revisão da literatura. Os sete fatores extraídos da literatura que foram utilizados como ponto de partida para a discussão do estudo exploratório eram: 
- Alinhamento estratégico

- Envolvimento da gerencia e liderança

- Utilização de ferramentas e metodologia

- Aprendizagem organizacional

- Capacitação e treinamento Desenvolvimento de talentos

- Cultura - engajamento e envolvimento das pessoas e colaboradores

- Estrutura de suporte e governança para o programa

\subsection{Etapa exploratória}

O estudo exploratório, realizado a posteriori, buscou explorar com especialistas da área as afirmativas e fatores que impactam na sustentação dos programas de melhoria contínua. Estes especialistas, todos consultores e implantadores de projetos de larga experiência que atuaram em diferentes indústrias e com relevante background acadêmico, envolvendo pósgraduação, certificação em melhoria contínua e experiência na condução de projetos e programas, contribuíram com o estudo exploratório em quatro etapas:

1. Preenchimento do formulário e atribuição individual das afirmativas extraídas da literatura, que inferiam sobre os programas ou projetos de melhoria contínua, aos fatores: envolveu dados introdutórios, pessoais e de background, aspectos relacionados a vivência com a melhoria contínua, aspectos relacionados ao resultado de uma implantação e a sustentabilidade da mesma. Também envolveram questões abertas relacionadas a preponderância de fatores (adição de elementos/fatores que assegurem o êxito de um programa de melhoria contínua a longo prazo); os especialistas poderiam adicionar fatores se julgassem que algum elemento não estaria associado aos fatores iniciais.

2. Alinhamento interno entre os especialistas, o qual gerou uma discussão entre eles sobre as afirmativas e fatores, permitindo incorporar afirmativas a outros fatores bem como recombinar as afirmativas e fatores

3. Refinamento e operacionalização das afirmativas e fatores citados por eles às referências da literatura

4. Operacionalização e sintetização das afirmativas em variáveis operacionalizadas.

\section{RESULTADOS E DISCUSSÃO}

Os especialistas realizaram o trabalho de identificação de fatores e variáveis explorando os conceitos trazidos pela literatura e discutindo entre si posteriormente. Os resultados foram obtidos a partir de um processo metodológico de 4 etapas, já mencionado. Numa primeira etapa os especialistas identificaram 103 afirmativas atribuídas a 12 fatores. Os cinco fatores adicionados aos sete iniciais foram: Suporte dos especialistas; Foco no cliente; Premiação e reconhecimento; Benchmarking; Envolvimento de parceiros.

A segunda etapa envolveu uma discussão e alinhamento entre os especialistas e os autores, chegando a uma convergência na elaboração da lista de afirmativas em fatores, seja por concordância total ou parcial. As discussões foram importantes e geraram uma série de conclusões, pois houveram agrupamentos e quebras de fatores. Os resultados da discussão contemplando os reagrupamentos foram:

- Estrutura de Suporte e Governança reorganizada em dois fatores: Governança do Programa e Infraestrutura.

- Capacitação e Treinamento Desenvolvimento de talentos converteuse em: Capacitação e treinamento e Suporte RH.

- Foi mencionado por um dos especialistas, a importância da área de finanças para validar as melhorias durante a execução do programa, o que gerou aceitação dos demais e a inclusão do fator Suporte de finanças isoladamente.

- Os especialistas também afirmaram ser a Comunicação ser um elo entre o alinhamento estratégico e o envolvimento da liderança. A comunicação é fundamental para que todas as faces da organização vivenciem uma jornada de transformação. Houve um consenso sobre essa proposição a qual gerou um novo fator: Comunicação.

A partir desta adequação de fatores, as afirmativas foram redistribuídas, através de um consenso, a estes 16 fatores. O quadro 2 apresenta a lista dos fatores e o número de afirmativas atribuídas a eles pelos especialistas. 
Avaliação de Fatores e Variáveis que Influenciam a Sustentação de Programas de Melhoria Contínua na Visão de Especialistas

Quadro 2 - lista dos fatores e o número de afirmativas atribuídas a eles pelos especialistas.

\begin{tabular}{|c|c|c|c|}
\hline Id & Fatores & Justificativa & $\begin{array}{c}\text { Número de } \\
\text { Afirmativas }\end{array}$ \\
\hline 1 & $\begin{array}{l}\text { Alinhamento } \\
\text { Estratégico }\end{array}$ & $\begin{array}{l}\text { Os programas de melhoria devem estar alinhados à visão e missão estratégica da } \\
\text { organização. }\end{array}$ & 6 \\
\hline 2 & Liderança & $\begin{array}{l}\text { A liderança é o veículo de comunicação da alta administração para os } \\
\text { funcionários e seu papel é fundamental no envolvimento do programa. Assim } \\
\text { ela deve estar comprometida, buscando envolver e suportar seus liderados. }\end{array}$ & 4 \\
\hline 3 & Comunicação & $\begin{array}{l}\text { A comunicação do programa precisa ser bem realizada de forma a informar a } \\
\text { organização quais serão os objetivos finais do programa. Ela deve divulgar a } \\
\text { visão estratégica através do programa. }\end{array}$ & 4 \\
\hline 4 & $\begin{array}{l}\text { Governança do } \\
\text { Programa }\end{array}$ & $\begin{array}{l}\text { Processo de gestão do programa para assegurar que a estratégia seja seguida, } \\
\text { que o plano seja estabelecido e alinhados aos objetivos do negócio, que a } \\
\text { comunicação seja realizada, que a liderança execute seu papel, que o suporte } \\
\text { financeiro seja realizado, que as ferramentas e metodologias e especialistas } \\
\text { estejam disponíveis, que os projetos e as pessoas sejam bem selecionados e } \\
\text { definidos, e que o acompanhamento das implantações seja bem realizado. }\end{array}$ & 12 \\
\hline 5 & Infraestrutura & $\begin{array}{l}\text { Suporte da organização para adequar os recursos, o ambiente, aspectos } \\
\text { tecnológicos e sócio culturais. Avaliam-se aspectos da estrutura organizacional } \\
\text { quanto à adesão a um programa de melhoria contínua. }\end{array}$ & 4 \\
\hline 6 & Suporte Finanças & $\begin{array}{l}\text { Os projetos de melhoria requerem um acompanhamento e validação financeira } \\
\text { dos benefícios capturados, uma vez que um programa requer um retorno } \\
\text { financeiro para a empresa. Importante existir uma pessoa de finanças nomeada } \\
\text { para apurar os resultados do projeto. }\end{array}$ & 1 \\
\hline 7 & $\begin{array}{l}\text { Aprendizagem } \\
\text { Organizacional }\end{array}$ & $\begin{array}{l}\text { Envolve aspectos mais humanos relacionados ao trabalho colaborativo, à } \\
\text { compreensão e aprendizado contínuo, ao engajamento e motivação das pessoas, } \\
\text { através da liberdade criativa, para executarem seu trabalho e o aprimorarem } \\
\text { continuamente. Compreende a habilidade de integrar, construir e reconfigurar } \\
\text { competências internas e externas de forma rápida, propiciando rápidas } \\
\text { mudanças nos ambientes. }\end{array}$ & 7 \\
\hline 8 & Cultura & $\begin{array}{l}\text { Aspectos culturais presentes na organização que sinalizam o nível de resistência } \\
\text { de adesão ao programa. Estruturas top-down são organizações menos aderentes } \\
\text { a programas de mudança e melhoria contínua. Organizações bottom-up } \\
\text { incentivam a criatividade e liberdade criativa têm uma maior compatibilidade } \\
\text { aos programas de transformação. }\end{array}$ & 10 \\
\hline 9 & $\begin{array}{c}\text { Premiação e } \\
\text { Reconhecimento }\end{array}$ & $\begin{array}{l}\text { Incentivo e sugestões também aumentam a motivação da equipe gerando } \\
\text { benefícios financeiros e premiações. }\end{array}$ & 3 \\
\hline 10 & Treinamento & $\begin{array}{l}\text { Capacitação para executar a metodologia de forma estruturada. Treinamentos } \\
\text { mais sêniores para especialistas, treinamentos Green Belt para os líderes de } \\
\text { projetos e treinamentos de utilização de ferramentas básicas de melhoria são } \\
\text { necessários para a equipe do projeto. Importante um planejamento de carreira } \\
\text { para os especialistas e pessoas que se destacam na execução dos projetos de } \\
\text { melhoria, pois assegura a motivação das pessoas. }\end{array}$ & 5 \\
\hline 11 & Suporte RH & $\begin{array}{l}\text { Assegura alinhamento do programa de melhoria contínua à gestão de recursos } \\
\text { humanos. Missão de minimizar resistências e controvérsias ao longo de uma } \\
\text { jornada de transformação, gerir expectativas e garantir a disponibilidade dos } \\
\text { recursos, negociando com a liderança. }\end{array}$ & 16 \\
\hline 12 & $\begin{array}{l}\text { Técnicas e } \\
\text { Ferramentas }\end{array}$ & $\begin{array}{l}\text { Entendimento técnico e metodológico para aplicação dos conceitos e técnicas de } \\
\text { melhoria contínua garantindo o êxito de um programa. Realizar um evento } \\
\text { Kaizen ou executar um projeto dentro de um programa percorrendo o ciclo } \\
\text { DMAIC - definir, medir, analisar, implantar e controlar é fundamental diante de } \\
\text { um processo de melhoria contínua }\end{array}$ & 19 \\
\hline 13 & $\begin{array}{c}\text { Suporte } \\
\text { Especialistas }\end{array}$ & $\begin{array}{l}\text { Aprimoramento da metodologia com o conhecimento e a experiência dos } \\
\text { especialistas. Assegurar a participação e envolvimento de especialistas sêniores } \\
\text { no suporte metodológico do projeto é fundamental. Especialistas têm a } \\
\text { finalidade de aportar conhecimento nos projetos gerando sempre benefícios } \\
\text { adicionais. }\end{array}$ & 3 \\
\hline 14 & $\begin{array}{c}\text { Cadeia } \\
\text { Fornecedores }\end{array}$ & $\begin{array}{l}\text { Envolvimento de fornecedores e parceiros na busca pela melhoria contínua. } \\
\text { Importante para uma organização é, sua cadeia estar engajada na jornada de } \\
\text { transformação }\end{array}$ & 2 \\
\hline 15 & Objetivos Cliente & $\begin{array}{l}\text { Entender os valores do cliente que geram resultados para o negócio. Estabelecer } \\
\text { foco na competitividade e no mercado para gerar melhores resultados e } \\
\text { melhores desempenhos. }\end{array}$ & 6 \\
\hline 16 & Benchmarking & $\begin{array}{l}\text { Buscar as melhores práticas no mercado para trazer inovação aos processos } \\
\text { organizacionais. }\end{array}$ & 1 \\
\hline
\end{tabular}


A terceira etapa representou uma comparação das afirmativas e fatores às referências da literatura. Avaliou-se simplesmente o número de afirmativas agrupadas por fator pelos especialistas (eixo das abcissas) versus o número de vezes que pelo menos uma afirmativa de um dado fator foi citada por autores distintos (eixo das ordenadas). Obviamente a percepção dos autores era sobre as afirmativas extraídas por eles próprios da literatura, mas que agora refletiam nos fatores atribuídos pelos especialistas.

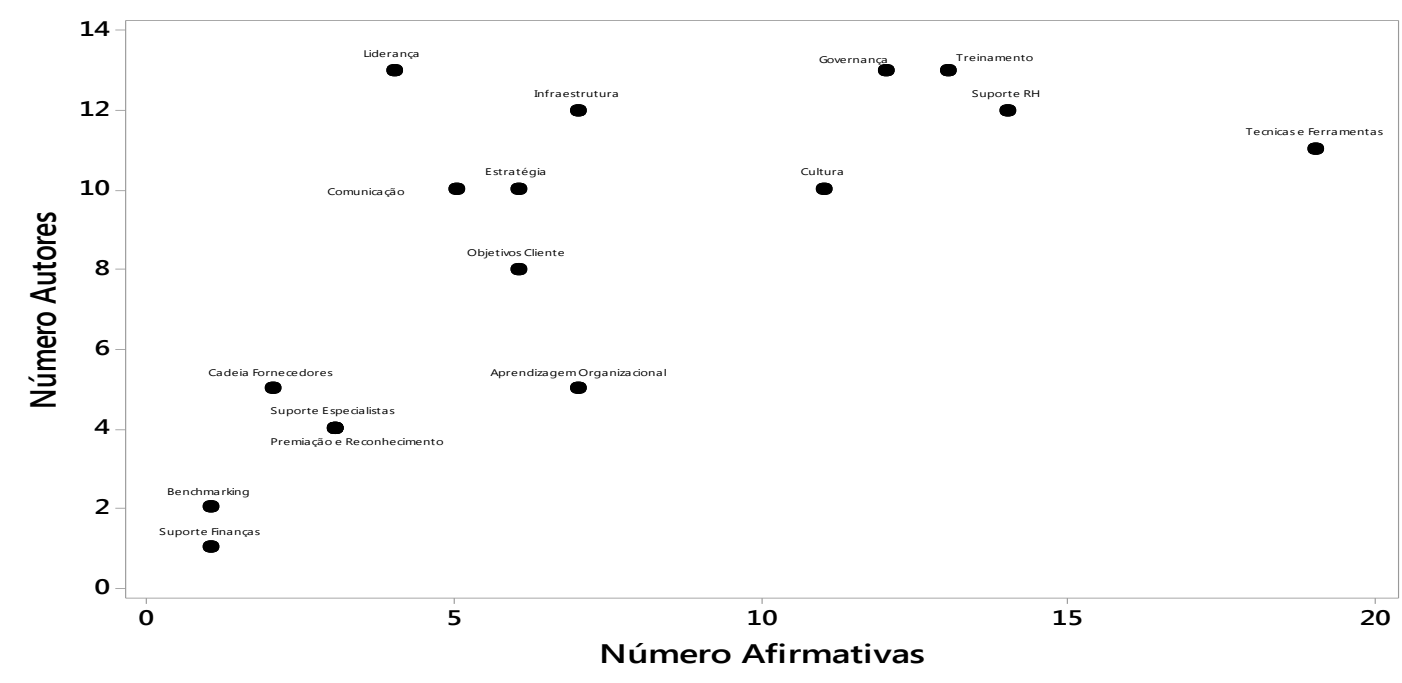

Gráfico 1 - Representatividade dos Fatores em termos de afirmativas e de referências distintas

Os resultados do gráfico 1 mostraram que 11 fatores são mencionados por pelo menos 5 autores, sendo alguns deles (técnicas e ferramentas, suporte RH, governança do programa e cultura, mais densos quanto ao número de afirmativas). Por outro lado, existem cinco fatores: Suporte Finanças, Benchmark, Suporte de Especialistas, Premiação e Reconhecimento e Cadeia de Fornecedores, que são pouco mencionados pelos autores e apresentam poucas afirmativas atribuídas pelos especialistas. Com base neste resultado, uma discussão com os especialistas sobre estes cinco fatores, foi realizada neste estudo exploratório com o intuito de avaliar a sua permanência ou buscar eventual reagrupamento com outro fator. Nesta avaliação de fatores foram julgados a importância e caso entendessem que era importante, avaliou-se o número de afirmativas, pois poucas afirmativas para representar um fator, quando comparado a fatores de muitas afirmativas poderiam qualificar ou desqualificar um dado fator inteiramente.

De acordo com os especialistas, alguns destes fatores são fundamentais, justificados por eles da seguinte forma:

- O fator de Suporte Financeiro é importante para mostrar o comprometimento da organização com o benefício potencial e isto gera comprometimento tanto da execução como da liderança em motivar a busca pelo resultado.
- Quanto ao fator de Premiação e $\underline{\text { Reconhecimento, }}$ ele tem um forte aspecto motivador e que influencia diretamente no engajamento das pessoas a encontrarem e propor solução para as ações de melhoria.

- A respeito do suporte dos especialistas e benchmark, a importância reside na inovação constante da metodologia, fundamental na visão dos especialistas para fomentar e constantemente inovar a melhoria contínua.

- Por outro lado, o fator de cadeia de fornecedores foi qualificado pelos especialistas como secundário para a sustentação de um programa de melhoria por entender que a extensão para a cadeia não inviabiliza o sucesso de um programa. Sendo assim, ele foi excluído.

Por outro lado, pelo baixo número de afirmativas atribuídas a estes 4 fatores, decidiu-se reagrupá-los da seguinte forma:

- Suporte Financeiro foi incorporado a Governança do Programa que 
compreende o processo de gestão do programa para assegurar que a estratégia seja seguida, que o plano seja estabelecido e que os projetos estejam alinhados aos objetivos do negócio, que a comunicação seja realizada, que a liderança execute seu papel, que o suporte financeiro seja realizado, que as ferramentas e metodologias e especialistas estejam disponíveis, que os projetos e as pessoas sejam bem selecionados e definidos, e que o acompanhamento das implantações seja bem realizado.

- A respeito do suporte dos especialistas e benchmark, eles foram agrupados em um único fator denominado Suporte dos Especialistas pois os especialistas têm também um papel de buscar continuamente a inovação em termos metodológicos, fazendo benchmark externo, para poder suportar os programas da melhor forma possível.

- Premiação e reconhecimento foi conservado isoladamente.

Desta forma, definiu-se 13 fatores para serem estudados através de uma abordagem quantitativa buscando entender a influência e impacto na sustentação dos programas de melhoria contínua.

A quarta e última etapa do estudo exploratório envolveu uma operacionalização e sintetização das afirmativas em variáveis, uma vez que similaridades foram encontradas. Assim as 103 afirmativas foram reescritas e sintetizados em 79 variáveis, atribuídas aos 13 fatores.

O Quadro 3 mostra a lista dos fatores e variáveis reescritas e sintetizadas.

Quadro 3 - lista dos fatores e variáveis reescritas e sintetizadas.

\begin{tabular}{|c|c|c|}
\hline$\#$ & Fator & Variável \\
\hline 1 & Comunicação & $\begin{array}{l}\text { Empresa deve dar o direcionamento da estratégia e objetivos e metas aos colaboradores } \\
\text { de forma a obter colaboração e comprometimento. }\end{array}$ \\
\hline 2 & Comunicação & Empresa deve comunicar (ao longo do programa) os sucessos e as falhas \\
\hline 3 & Comunicação & $\begin{array}{l}\text { Empresa deve manter uma comunicação ativa com todos os envolvidos das ações do } \\
\text { programa de melhoria }\end{array}$ \\
\hline 4 & Comunicação & $\begin{array}{l}\text { Colaborador compreender as metas e objetivos da organização para com o programa de } \\
\text { melhoria }\end{array}$ \\
\hline 5 & Cultura & Empresa estar aberta a mudanças \\
\hline 6 & Cultura & $\begin{array}{l}\text { Membros dos programas de melhoria contínua apresentarem uma estrutura de trabalho } \\
\text { colaborativa }\end{array}$ \\
\hline 7 & $\begin{array}{l}\text { Aprendizagem } \\
\text { Organizacional }\end{array}$ & $\begin{array}{l}\text { Membros dos programas de melhoria contínua aprenderem com os problemas sejam } \\
\text { positivos ou negativos }\end{array}$ \\
\hline 8 & $\begin{array}{l}\text { Aprendizagem } \\
\text { Organizacional }\end{array}$ & $\begin{array}{l}\text { Membros dos programas de melhoria contínua compartilharem entendimento dos } \\
\text { processos chaves e suas características criticas }\end{array}$ \\
\hline 9 & $\begin{array}{l}\text { Aprendizagem } \\
\text { Organizacional }\end{array}$ & $\begin{array}{l}\text { Membros dos programas de melhoria contínua se basearem na análise e Solução de } \\
\text { problemas e implementarem ações rapidamente }\end{array}$ \\
\hline 10 & $\begin{array}{l}\text { Aprendizagem } \\
\text { Organizacional }\end{array}$ & $\begin{array}{l}\text { Aprendizado de indivíduos e times durante as ações de melhoria serem capturados para } \\
\text { uso futuro }\end{array}$ \\
\hline 11 & $\begin{array}{l}\text { Aprendizagem } \\
\text { Organizacional }\end{array}$ & Aprendizado de indivíduos e times serem implantados em ações futuras \\
\hline 12 & Cultura & $\begin{array}{l}\text { Colaboradores terem uma cultura de suporte e engajamento proativo para realizarem } \\
\text { melhorias incrementais }\end{array}$ \\
\hline 13 & Cultura & Membros dos programas de melhoria contínua manterem seus valores culturais \\
\hline 14 & $\begin{array}{l}\text { Aprendizagem } \\
\text { Organizacional }\end{array}$ & Membros dos programas de melhoria contínua terem uma mentalidade de zero defeitos \\
\hline 15 & Cultura & $\begin{array}{l}\text { Existirem Mecanismos motivadores (treinamentos e trabalhos em time) usados para } \\
\text { envolver os times de melhoria continua }\end{array}$ \\
\hline 16 & Cultura & $\begin{array}{l}\text { Assessment assegurando que a estrutura organizacional, sistemas e procedimentos, } \\
\text { treinamentos e o mecanismo usado para desenvolver MC, está ativo e gerando } \\
\text { motivação para o programa }\end{array}$ \\
\hline 17 & Cultura & $\begin{array}{l}\text { Empresa incorporar a filosofia de melhoria contínua para maximizar o valor agregado } \\
\text { de um programa (ou das ações) }\end{array}$ \\
\hline 18 & Estratégia & $\begin{array}{l}\text { Empresa apresentar um planejamento estratégico e uma visão de médio e longo prazo } \\
\text { com detalhamento do plano }\end{array}$ \\
\hline
\end{tabular}


Avaliação de Fatores e Variáveis que Influenciam a Sustentação de Programas de Melhoria Contínua na Visão de Especialistas

\begin{tabular}{|c|c|c|}
\hline \# & Fator & Variável \\
\hline 19 & Estratégia & $\begin{array}{l}\text { Empresa se preocupar em alinhar a estratégia do negócio às necessidades da } \\
\text { organização }\end{array}$ \\
\hline 20 & Estratégia & $\begin{array}{l}\text { Empresa desenvolver Estratégia de Melhoria Contínua e um plano para implantação do } \\
\text { programa }\end{array}$ \\
\hline 21 & Estratégia & Programa de melhoria contínua envolver todo o negócio da empresa \\
\hline 22 & Estratégia & $\begin{array}{l}\text { Empresa se preocupar em alinhar o programa de melhoria a estratégia do } \\
\text { negócio/necessidades da organização }\end{array}$ \\
\hline 23 & Estratégia & $\begin{array}{l}\text { Colaboradores envolvidos com o Programa usarem os objetivos e metas estratégicas } \\
\text { para focarem e priorizarem suas atividades de melhoria }\end{array}$ \\
\hline 24 & Infraestrutura & $\begin{array}{l}\text { Empresa apresentar uma infraestrutura organizacional para realizar melhorias - } \\
\text { especialistas, liderança que apoie, treinamento, cultura de envolvimento, gestão }\end{array}$ \\
\hline 25 & Infraestrutura & $\begin{array}{l}\text { Realizar adequado investimentos em recursos: pessoas, gestão, tecnologia, processos, } \\
\text { capacitação }\end{array}$ \\
\hline 26 & Infraestrutura & $\begin{array}{l}\text { Empresa apresentar uma operação flexível (apta a fazer ajustes) para realizar Melhoria } \\
\text { Contínua }\end{array}$ \\
\hline 27 & $\begin{array}{l}\text { Governança do } \\
\text { Programa }\end{array}$ & $\begin{array}{l}\text { Líderes preocuparem-se em selecionar e priorizar os projetos, de preferência os críticos } \\
\text { e de maior impacto }\end{array}$ \\
\hline 28 & $\begin{array}{l}\text { Governança do } \\
\text { Programa }\end{array}$ & Líderes preocuparem-se em selecionar as pessoas para liderar os projetos \\
\hline 29 & $\begin{array}{l}\text { Governança do } \\
\text { Programa }\end{array}$ & $\begin{array}{l}\text { Champions e padrinhos implementarem um estruturado processo de acompanhamento } \\
\text { e fechamento dos projetos }\end{array}$ \\
\hline 30 & $\begin{array}{l}\text { Governança do } \\
\text { Programa }\end{array}$ & $\begin{array}{l}\text { Assegurar foco com o escopo evitando mudanças de acordo com as necessidades do } \\
\text { negócio }\end{array}$ \\
\hline 31 & $\begin{array}{l}\text { Governança do } \\
\text { Programa }\end{array}$ & Assegurar foco com os objetivos, escopo e metas dos projetos \\
\hline 32 & $\begin{array}{l}\text { Governança do } \\
\text { Programa }\end{array}$ & Haver um plano para sustentar as melhorias já no início do projeto/iniciativa \\
\hline 33 & $\begin{array}{l}\text { Governança do } \\
\text { Programa }\end{array}$ & $\begin{array}{l}\text { Líder do programa apresentar Habilidade para gerir o programa end to end, medindo a } \\
\text { evolução e provendo feedbacks }\end{array}$ \\
\hline 34 & $\begin{array}{l}\text { Governança do } \\
\text { Programa }\end{array}$ & $\begin{array}{l}\text { Líder estabelecer uma matriz completa sobre o programa: líder do time, escopo e } \\
\text { metas, champion, sponsor e especialista }\end{array}$ \\
\hline 35 & Liderança & Liderança construir um envolvimento cultural de times e empregados \\
\hline 36 & Liderança & Liderança / gerencia estar envolvida e comprometida \\
\hline 37 & Liderança & $\begin{array}{l}\text { Desenvolver líderes que compreendam completamente o trabalho, que vivam a } \\
\text { filosofia e a ensinem aos outros. }\end{array}$ \\
\hline 38 & Liderança & Liderança suportar os times de melhoria \\
\hline 39 & Visão no cliente & Programa de melhoria estar alinhado aos valores e necessidades do cliente \\
\hline 40 & Visão no cliente & $\begin{array}{l}\text { Programa de Melhoria estar focado nos resultados para o cliente (Velocidade, } \\
\text { qualidade, preço) }\end{array}$ \\
\hline 41 & $\begin{array}{c}\text { Premiação e } \\
\text { Reconhecimento }\end{array}$ & $\begin{array}{l}\text { Empresa possuir um programa de incentivo para envolver os colaboradores na geração } \\
\text { de melhorias }\end{array}$ \\
\hline 42 & $\begin{array}{c}\text { Premiação e } \\
\text { Reconhecimento }\end{array}$ & Empresa premiar os indivíduos responsáveis pelas ações implementadas \\
\hline 43 & $\begin{array}{c}\text { Premiação e } \\
\text { Reconhecimento }\end{array}$ & $\begin{array}{l}\text { Empresa reconhecer e prover carreira para os colaboradores motivados na realização de } \\
\text { ações de melhoria }\end{array}$ \\
\hline 44 & $\begin{array}{c}\text { Premiação e } \\
\text { Reconhecimento }\end{array}$ & $\begin{array}{l}\text { Empresa possuir um sistema de avaliação e acompanhamento das ações implantadas } \\
\text { para avaliar a eficácia do plano de incentivos e premiações }\end{array}$ \\
\hline 45 & $\begin{array}{c}\text { Suporte } \\
\text { Especialistas }\end{array}$ & Especialistas possuírem conhecimento e habilidades para suportarem os projetos \\
\hline 46 & $\begin{array}{c}\text { Suporte } \\
\text { Especialistas }\end{array}$ & Especialistas possuírem tempo para suportarem os projetos \\
\hline 47 & $\begin{array}{l}\text { Governança do } \\
\text { Programa }\end{array}$ & Existir um responsável da área de finanças para validar as melhorias \\
\hline 48 & Suporte RH & Gestão da Mudança gerir conflitos e controvérsias \\
\hline 49 & Suporte RH & Recursos Humanos desenvolver pessoas e equipes excepcionais e que sigam a filosofia \\
\hline
\end{tabular}


Avaliação de Fatores e Variáveis que Influenciam a Sustentação de Programas de Melhoria Contínua na Visão de Especialistas

\begin{tabular}{|c|c|c|}
\hline \# & Fator & Variável \\
\hline & & da empresa. \\
\hline 50 & Suporte RH & Recursos Humanos gerenciar Expectativas de carreira dos talentos \\
\hline 51 & Suporte RH & RH e gestão da mudança minimizar e trabalhar a resistência interna \\
\hline 52 & Suporte RH & RH trabalhar a Disponibilidade de Recursos \\
\hline 53 & Suporte RH & RH Envolver os colaboradores \\
\hline 54 & Suporte RH & Gestão da Mudança gerenciar o tamanho das equipes de melhoria \\
\hline 55 & Suporte RH & Gestão da Mudança promover atividades de melhoria contínua \\
\hline 56 & Suporte RH & RH utilizar os melhores talentos para garantir e executar os melhores projetos \\
\hline 57 & Suporte RH & RH assegurar cooperação e integração da equipe de melhoria contínua \\
\hline 58 & Suporte RH & RH entender o aspecto humano envolvido na condução dos projetos \\
\hline 59 & $\begin{array}{l}\text { Técnicas e } \\
\text { Ferramentas }\end{array}$ & Compreender as ferramentas e técnicas de melhoria contínua (Lean, Kaizen, DMAIC) \\
\hline 60 & $\begin{array}{c}\text { Técnicas e } \\
\text { Ferramentas }\end{array}$ & Utilizar as ferramentas e técnicas de melhoria contínua (Lean, Kaizen, DMAIC) \\
\hline 61 & $\begin{array}{c}\text { Técnicas e } \\
\text { Ferramentas }\end{array}$ & Utilizar de informação baseada em dados e fatos e realizar análise para tomar decisões \\
\hline 62 & $\begin{array}{c}\text { Técnicas e } \\
\text { Ferramentas }\end{array}$ & Utilizar ferramentas analíticas e estatísticas. \\
\hline 63 & $\begin{array}{c}\text { Técnicas e } \\
\text { Ferramentas }\end{array}$ & Utilizar ferramentas de MASP (Método de análise e solução de problemas) \\
\hline 64 & $\begin{array}{c}\text { Técnicas e } \\
\text { Ferramentas }\end{array}$ & Criar o fluxo de processo contínuo para trazer os problemas à tona. \\
\hline 65 & $\begin{array}{c}\text { Técnicas e } \\
\text { Ferramentas }\end{array}$ & Utilizar sistemas puxados para evitar a superprodução. \\
\hline 66 & $\begin{array}{c}\text { Técnicas e } \\
\text { Ferramentas }\end{array}$ & $\begin{array}{l}\text { Nivelar a carga de trabalho (a partir do heijunka). Trabalhar cadenciado preservando a } \\
\text { qualidade e a segurança }\end{array}$ \\
\hline 67 & $\begin{array}{c}\text { Técnicas e } \\
\text { Ferramentas }\end{array}$ & Utilizar controle visual para que nenhum problema fique oculto. \\
\hline 68 & $\begin{array}{c}\text { Técnicas e } \\
\text { Ferramentas }\end{array}$ & $\begin{array}{l}\text { Utilizar somente tecnologia confiável e completamente testada que atenda aos } \\
\text { funcionários e processos. }\end{array}$ \\
\hline 69 & $\begin{array}{c}\text { Técnicas e } \\
\text { Ferramentas }\end{array}$ & $\begin{array}{l}\text { Ver por si mesmo os problemas e oportunidades para compreender completamente a } \\
\text { situação (ir ao "Gemba") }\end{array}$ \\
\hline 70 & $\begin{array}{c}\text { Técnicas e } \\
\text { Ferramentas }\end{array}$ & Trabalhar na padronização de ferramentas metodológicas \\
\hline 71 & $\begin{array}{c}\text { Técnicas e } \\
\text { Ferramentas }\end{array}$ & Realizar assessment e auditorias \\
\hline 72 & $\begin{array}{c}\text { Técnicas e } \\
\text { Ferramentas }\end{array}$ & $\begin{array}{l}\text { Incorporar um processo de decisão gerencial que baseia cada decisão no relativo } \\
\text { impacto para o cliente }\end{array}$ \\
\hline 73 & $\begin{array}{c}\text { Técnicas e } \\
\text { Ferramentas }\end{array}$ & $\begin{array}{l}\text { Promover metodologias que buscam minimizar variação das características de } \\
\text { qualidade }\end{array}$ \\
\hline 74 & $\begin{array}{c}\text { Suporte } \\
\text { Especialistas }\end{array}$ & Espelharem-se nas boas práticas \\
\hline 75 & Treinamento & Focar na melhoria e resultado e não no treinamento por si só \\
\hline 76 & Treinamento & Idêntica corretamente os recursos para o treinamento \\
\hline 77 & Treinamento & $\begin{array}{l}\text { Assegurar que as tarefas padronizadas são a base para a melhoria contínua e a } \\
\text { capacitação dos funcionários. }\end{array}$ \\
\hline 78 & Treinamento & Prover um plano / programa de treinamento em Melhoria Contínua \\
\hline 79 & Treinamento & Educar, premiar e reconhecer os colaboradores dos times de melhoria \\
\hline
\end{tabular}

Desta forma, o estudo qualitativo identificou um conjunto de variáveis associados a diferentes fatores que são importantes para a sustentação de um programa de melhoria contínua. As variáveis foram associadas aos fatores por um conjunto de especialistas seniores em melhoria contínua e foi amplamente 
debatida entre eles e os autores. O trabalho permitiu apontar 79 variáveis e 13 fatores como importantes para sustentar um programa de melhoria contínua. Fica claro que além da utilização das ferramentas técnicas e o bom uso da metodologia, há um conjunto de outros 12 fatores relacionados a governança, alinhamento estratégico, infraestrutura e envolvimento dos times, cultura e treinamento, que impactam na sustentação dos programas de melhoria contínua.

De uma forma geral, estes resultados estão em concordância com a literatura pesquisada inicialmente, em que Brown (2013) apresenta elementos de sucesso para os programas de melhoria contínua dando mais ênfase ao uso de metodologia e técnicas e ferramentas, mas não descarta a importância de liderança, estratégia e comunicação. Por outro lado, Coronado e Antony (2002) dão maior ênfase aos aspectos de comprometimento, envolvimento cultural, comunicação, infraestrutura e treinamento, conectando esses elementos aos fatores técnicos. Já Bhuiyan e Baghel (2005), Liker (2005) e Snee (2010), afirmam ser a melhoria contínua composta de sinergia entre a metodologia técnica, o envolvimento e engajamento dos colaboradores somada a uma contínua rotina de treinamento, concentrando-se no conceito do aprendizado contínuo. De acordo com Liker (2005), o segredo do sucesso de um programa de melhoria contínua está no desenvolvimento de uma cultura voltada a aprendizagem, o que concorda com o resultado identificado pelo estudo exploratório com os especialistas.

Os resultados apresentados pelo trabalho concordam com a literatura sem apontar preponderância de um fator em relação aos outros, algo que pode ser complementado com uma análise quantitativa posteriormente, de forma a avaliar $o$ impacto ou a força de influência de cada fator na sustentação dos programas de melhoria contínua. Contudo, a contribuição deste trabalho foi a de identificar os fatores de forma clara e contundente, algo que a literatura não tinha realizado de maneira expositiva, pois aspectos relacionados a cultura, se misturavam com aspectos de aprendizagem organizacional e governança e aspectos de liderança, estratégia e comunicação não estavam bem estabelecidos. A lista de fatores e variáveis permitirá mensurar a aplicabilidade de um constructo na sustentação dos programas de melhoria continua, a partir das variáveis atribuídas a ele.

\section{CONCLUSÃO}

Este trabalho de abordagem qualitativa possibilitou identificar os fatores que impactam na sustentação dos resultados dos programas de melhoria contínua, a partir de uma extração de afirmativas e fatores explícitos da literatura, seguidos de um estudo exploratório com especialistas. Foi possível identificar e relacionar as 79 variáveis que foram atribuídas a 13 fatores.

Os resultados deste trabalho corroboram e reforçam o argumento de Liker (2005), Bhuiyan e Baghel (2005) e Snee (2010) de que o êxito de um programa de melhoria contínua é mais do que a simples aplicação de bons conceitos e ferramentas de Lean e Seis Sigma. Faz-se necessário agregar outros fatores tais como:

- Um bom alinhamento do programa a estratégia da organização,

- Uma boa estratégia de comunicação para os níveis da organização de forma a gerar comprometimento e envolvimento seja para a liderança ou para o colaborador atuante,

- Incentivar o trabalho colaborativo através de aprendizagem organizacional,

- Incentivar a geração de ideias e premiá-las,

- Valorizar uma cultura de mudança aliada ao programa e incentivada pelo trabalho colaborativo que incentiva a aprendizagem organizacional,

- Enfocar em treinamento e capacitação dos indivíduos que se destacam na aplicação de treinamentos e neste caso,

- Envolver a equipe de recursos humanos é fundamental para trilhar a carreira e reter estes talentos,

- Agregar aspectos de governança do programa para assegurar $\mathrm{o}$ cumprimento das atividades e evitar os desvios de rota,

- Preparar a organização em termos de ferramentas de gestão operacional e desempenho para aplicar bem a metodologia,

- Adequar uma infraestrutura envolvendo ou não tecnologia para garantir que os dados estejam adequados e que permitam gerar ações de melhoria rápidas e assertivas é fundamental,

- Participar os especialistas sêniores que tem o papel de aportar a metodologia atualizada, solucionar os problemas complexos e garantir a implantação é fundamental para o sucesso de um programa.

Logo, este trabalho gerou como produto uma lista de fatores que sob o ponto de vista acadêmico, devem ser considerados para a sustentação dos programas de melhoria contínua. Na visão dos autores, este conjunto de fatores seriam recomendações de 
implantação para as empresas de manufatura ou serviços que buscam benefícios de aumento de capacidade, melhoria de qualidade ou redução de custo operacional. Este trabalho gera e formata uma lista de fatores e variáveis requeridos durante a implantação de um programa. As variáveis e consequentemente os fatores, serão futuramente mensurados, através de uma análise quantitativa, de modo a entender o nível de importância de cada fator na sustentação dos programas de melhoria contínua.

\section{REFERÊNCIAS}

Antony, J. (2004). Some pros and cons of Six Sigma: an academic perspective. The TQM Magazine. 16(4), 303-306.

Arnheiter, E. D. \& Maleyeff, J. (2005). The integration of Lean Management and Six Sigma. The TQM Magazine. 17 (1), 5-18.

Attadia, L. \& Martins, R. A. (2003). A medição de desempenho como base para a evolução da MC: um estudo teórico. Produção. 13 (2), 33-41.

Barney, J. (1991). Firm Resources and Sustained Competitive Advantage. Journal of Management. 17 (1), 99-120.

Bessant, J., Caffyn, S., \& Gallagher, M. (2001). An evolutionary model of continuous improvement behavior. Technovation. 21, 67-77.

Bessant, J., Caffyn, S., Gilbert, J., Harding, R., \& Webb, S. (1994). Rediscovering continuous improvement. Technovation. 14 (1), 17-29.

Bessant J, Cafyn S (1997). High-investment innovation through continuous improvement. International Journal of Technology Management .14, 14-22.

Bhuiyan, N., \& Baghel, A. (2005). An overview of continuous Improvement: from past to presente. Management Decision. 43 (5), 761 - 77

Bourne, M., Kennerley, M., \& Franco-Santos, M. (2005). Managing through measures: a study of impact on performance. Journal of Manufacturing Technology Management. 16 (4), 373-395.

Caffyn, S. (1999). Development of a continuous improvement self assessment tool. International Journal of Operations and Production Management. 19 (11), 38-53.

Caffyn, S., Bessant, J., \& Gallengher, M. (1997). Development and testing of the generic model for continuous improvement: a report of the EPSRC sponsored CIRCA project. t, Brighton: Center for
Research in Innovation Managemen - University of Brighton.

Coelho Junior, F. A., \& Borges-Andrade, J. E. (2008). Uso do conceito de aprendizagem em estudos relacionados ao trabalho e organizações. Paidéia (Ribeirão Preto). 18, 221-234.

George ML (2002). Lean Six Sigma-Combining Six Sigma Quality with Lean Speed. New York: McGraw Hill:

Henry, J.F. (2006). Management control systems and strategy: a resource-based perspective, Accounting. Organizations and Society. 31 (6), 529-558.

Hoerl, R., \& Snee, R. D. (2002). Statistical thinking: improving business performance. Pacific Grove, CA: Duxbury Press.

Imai, M. (1986). Kaizen: The Key To Japan's Competitive Success. New York: McGraw-Hill.

Johnson, G., Scholes, K. and Whittington, R. (2008). Exploring Corporate Strategy: Text \& Cases, 8th ed., Harlow: Pearson Education,.

Juergensen, T. (2000). Continuous Improvement: Mindsets, Capability, Process, Tools and Results, Indianapolis: The Juergensen Consulting Group, Inc.

Kennerley, M.P., \& Neely, A.D. (2003). Measuring performance in a changing business environment. International Journal of Operations and Production Management. 23 (2), 213-229.

Kim, D. (1993). The link between individual and organizational learning. Sloan Management Review. 35 (1), 37-50.

Linderman, K. et al. (2003). Six Sigma: a goaltheoretic perspective. Journal of Operations Management. 3 (21), 193-203.

Liker, J. (2005). O modelo Toyota: 14 princípios de do maior fabricante do mundo. Porto Alegre: Bookman.

Ohno, T. (1997). O Sistema Toyota de Produção. Porto Alegre: Editora Artes Médicas Sul Ltda.

Schroeder DM, Robinson AG (1991). America's most successful export to Japan: continuous improvement programs. Sloan Manage. Rev. 32, 67-81.

Senge, P. M., Kleiner, A., Roberts, C., Ross, R., Smith, B., \& Brealy, N. (1994). The fifth discipline Fieldbook, New York: Currency Doubleday. 
Slack, N., Chambers, S., \& Johnston, R. (2007). Operations Management. Fith Edition, Harlow: Pearson Education.

Snee, R.D., \& Hoerl, R.W. (2007). Integrating lean and Six Sigma - a holistic approach. Six Sigma Forum Magazine. May 2007, 15-21.

Snee, R. D. (2008). W. Edwards Deming's 'Making a New World': a holistic approach to performance improvement and the role of statistics. The American Statistician. 6 (3), 251-5.

Snee, R. D. (2010). Lean Six Sigma - getting better all the time. International Journal of Lean Six Sigma. 1 (1), $9-29$.
Spear, S., \& Bowen, H. K. (1999). Decodying the DNA of Toyota System. Harvard Business Review.77 (5), 96-106.

Vanhonacker, F., Verbeke, W. (2014). Public and Consumer Policies for Higher Welfare Food Products: Challenges and Opportunities. Journal of Agricultural and Environmental Ethics. 27 (1), 153171.

Welch, J. and Welch, S. (2005), Winning, Harper Business. New York: Harper Business.

Yunus, M., \& Weber, K. (2010). Building social business: The new kind of capitalism that serves humanity's most pressing needs. New York: Public Affairs. 